\title{
Effect of long-acting erythropoiesis- stimulating agents on hemoglobin levels at the initiation of dialysis
}

\author{
Takasuke Asakawa', Yasuhiro Komatsu, Ryoichi Ando ${ }^{3}$, Nobuhiko Joki ${ }^{7}$, Yuri Tanaka ${ }^{1}$, Masaki Iwasaki ${ }^{1}$, Hiroki Hase ${ }^{1}$, \\ Masato Ikeda ${ }^{2}$, Daijo Inaguma ${ }^{5}$, Toshifumi Sakaguchi ${ }^{10}$, Toshio Shinoda ${ }^{4}$, Fumihiko Koiwa ${ }^{8}$, Shigeo Negi ${ }^{6}$, \\ Toshihiko Yamaka ${ }^{9}$ and Takashi Shigematsu ${ }^{6}$
}

\begin{abstract}
Background: The goal of the present study was to explore the differences in effects between erythropoiesisstimulating agent (ESA) types on hemoglobin $(\mathrm{Hb})$ level at the initiation of maintenance dialysis.

Methods: This was a cross-sectional study. From January 2006 to October 2012, 2920 patients with end-stage kidney disease commenced hemodialysis (HD) at nine participating hospitals. The criteria for exclusion from the database were (1) presence of cancer or gastrointestinal bleeding and (2) serum C-reactive protein $\geq 0.3 \mathrm{mg} / \mathrm{dL}$. A total of 1263 patients were entered into the final database. We explored the association of yearly trend of Hb level just before the first HD session with the different types of ESA in the predialysis period.

Results: During the 7-year study period, patients' Hb levels at the initiation of dialysis dramatically increased from 8.6 to $9.1 \mathrm{~g} / \mathrm{dL}$. Parallel to this increase, the use of long-acting ESA also increased from 0 to $80 \%$. A higher level of $\mathrm{Hb}$ was confirmed in the long-acting ESA group compared with the short-acting group ( $9.5 \mathrm{vs} .8 .7 \mathrm{~g} / \mathrm{dL}, P<0.01)$. Multivariate regression analysis showed a strong association of $\mathrm{Hb}$ level with the use of long-acting ESA $(r=0.155$, $P=0.003)$, even after adjusting for confounding variables and estimated dose of epoetin.
\end{abstract}

Conclusions: The change in the type of ESA used from short-acting to long-acting played a role in the increase of patients' $\mathrm{Hb}$ levels at the initiation of dialysis. A long-acting ESA has the potential effect of maintaining an optimal $\mathrm{Hb}$ level even in the advanced stages of CKD.

Keywords: Hemoglobin, Erythropoiesis-stimulating agents, Long-acting, Initiation of dialysis

\section{Background}

Anemia plays a crucial role in the promotion of cardiac remodeling and, consequently, in the onset of cardiac events in patients with chronic kidney disease (CKD) $[1,2]$. This is the reason why vigorous debate continues in the search for an optimal target hemoglobin $(\mathrm{Hb})$ level, achieved by treatment with an erythropoiesis-stimulating agent (ESA) for preventing cardiac abnormalities and events in the predialytic phase of CKD [3]. Unfortunately, even among CKD patients who receive ESA therapy, a higher percentage of anemia, with $\mathrm{Hb}$ levels $<11 \mathrm{~g} / \mathrm{dL}$, is

\footnotetext{
* Correspondence: jokinobuhiko@gmail.com

'Division of Nephrology, Toho University Ohashi Medical Center, 2-17-6

Ohashi, Meguro-ku, Tokyo 153-8515, Japan

Full list of author information is available at the end of the article
}

observed in patients in the more advanced stages of CKD [4]. Indeed, previous data from our multicenter study of Japanese dialysis patients clearly revealed that the mean $\mathrm{Hb}$ level at the initiation of dialysis was $8.5 \mathrm{~g} / \mathrm{dL}$ [5], which is lower than the target level recommended by current international guidelines [6-8]. It is also known that the onset of cardiac events such as congestive heart failure and myocardial ischemia increase close to the time of initiation of dialysis $[9,10]$. Although the evidence is still limited, we are assuming that this progression of anemia plays, at least in part, a role in the occurrence of cardiac events in the advanced stages of CKD. The occurrence of cardiac remodeling and events may decrease or become less severe if the $\mathrm{Hb}$ level could be kept at an optimum level-that is, over $10 \mathrm{~g} / \mathrm{dL}-$ even at the initiation of dialysis. 
Recently, the newer generation of ESAs has been changing to the long-acting type, such as darbepoetin and continuous erythropoietin receptor activators (CERA), rather than epoetin- $\alpha$ and $-\beta$. Referring to the dose conversion ratio from darbepoetin to epoetin [11], a higher prescribing dose of epoetin in the predialytic phase of CKD is theoretically more feasible than before. However, the evidence is still limited about the effect of long-acting ESAs on anemia in the advanced stages of CKD. The use of long-acting ESAs could increase the $\mathrm{Hb}$ level in the advanced stages of CKD. The goal of the present study was to explore the association of the yearly trend of mean $\mathrm{Hb}$ level with the change in the type of ESA used at the initiation of renal replacement therapy (RRT) during 2006-2012. Our hypothesis is that $\mathrm{Hb}$ level at the initiation of dialysis has increased after the introduction of the long-acting ESAs into the clinical practice compared with before their approval of clinical use.

\section{Methods}

\section{Study design and patients}

We conducted a retrospective study for cross-sectional comparative analysis of patients with ESKD among different eras by using the database of the Japanese Study Group for Assessing Initiation of Renal Replacement Therapy (J-START), which includes the nephrology units of nine teaching hospitals in Japan. The objective of JSTART is to create a shared database on end-stage kidney disease (ESKD) patients at the time of starting RRT for the conduct of clinical research. From January 2006 to October 2012, there were 2920 ESKD patients who commenced chronic hemodialysis (HD) at the nine hospitals. Clinical information on those patients was added to the J-START database. In order to explore the precise effect of ESAs on anemia, the ESKD patients with major etiological factors for low responsiveness to ESA [8] were excluded. The following exclusion criteria were employed: (1) gastrointestinal bleeding or other bleeding disease $(n=40)$, (2) cancer $(n=159)$, and (3) inflammation, with serum C-reactive protein (CRP) level $>0.3 \mathrm{mg} /$ $\mathrm{dL}(n=1458)$, such as in infectious disease or autoimmune disease. As a result, 1263 ESKD patients were available for inclusion in the database of this study. We explored the association of the yearly trend of the $\mathrm{Hb}$ levels just before patients' first HD session with the change of ESA type in the predialysis period. The clinical factors associated with $\mathrm{Hb}$ level were also explored.

The ethics committee for clinical research of Toho University Ohashi Medical Center approved the study protocol [permission No. 13-52, 13-61]. This study adhered to the Declaration of Helsinki. Informed consents to participate in this study and for the publication were obtained from all participants.

\section{Data collection}

Using the study protocol, clinical information was recorded for all patients at each nephrology unit immediately prior to their first HD session. Information was also collected on the use of oral medications and ESA per month during the predialysis period. Blood pressure (BP) was recorded in the supine position, and a blood sample was collected just before the first HD session. The comorbid conditions at the initiation of dialysis were reviewed from the medical records. The $\mathrm{Hb}$ was corrected by dose of ESA/1000 units. The estimated glomerular filtration rate (eGFR) was calculated by using the new Japanese equation [12]: eGFR (mL/min/ $\left.1.73 \mathrm{~m}^{2}\right)=194 \times \mathrm{Cr}^{-1.094} \times$ age $^{-0.287}(\times 0.739$ for women $)$. Body mass index (BMI) at optimal weight was calculated as the weight in kilograms divided by the square of the height in meters. Patients with "vascular access" were the patients for whom an arterio-venous fistula was surgically created according to a planned schedule before initiation of dialysis. Standard chest radiography proceeded on the day of the first HD session. The cardiothoracic ratio (CTR) was determined by dividing the maximal horizontal width of the heart by the horizontal inner width of the rib cage. Medications were classified as ESA, angiotensin-converting enzyme inhibitors (ACE-I), angiotensin-II receptor blockers (ARB), vitamin $\mathrm{D}$, iron agents, and AST-120. AST-120 is a carbonaceous adsorbent that is used to treat CKD patients in Japan. It has been reported that AST-120 removes uremic toxins and reduces oxidative stress [13, 14]. The duration of nephrologist care was defined as the length of followup days by nephrologists prior to the initiation of HD.

\section{ESA type}

In Japan, epoetin- $\alpha$ and $-\beta$ have been approved for use during the predialytic phase of CKD since 1995. Darbepoetin- $\alpha$ and methoxy polyethylene glycol-epoetin $\beta$ (Continuous Erythropoietin Receptor Activator; CERA) were registered in 2010 and 2011 respectively, all for use during the predialytic phase of CKD. Epoetin- $\alpha$ and $-\beta$ are short-acting ESAs, and darbepoetin- $\alpha$ and CERA are long-acting ESAs. The dose conversion ratios from darbepoetin- $\alpha$ and CERA to epoetin $\alpha / \beta$ were used 1:200 [15] and 1:270 [16] respectively.

\section{Statistical analysis}

Data are expressed as the mean $\pm \mathrm{SD}$, median [interquartile range], or percentage. Subject characteristics were compared across CKD stages using chi-square tests for categorical variables, analysis of variance (ANOVA) for normally distributed variables, and Kruskal-Wallis tests for non-normally distributed variables. As appropriate, the Jonckheere-Terpstra trend test was used for assessing the yearly trend of $\mathrm{Hb}$ concentration. To assess the 
Table 1 The characteristics of the study patients and temporal trends for 7 years

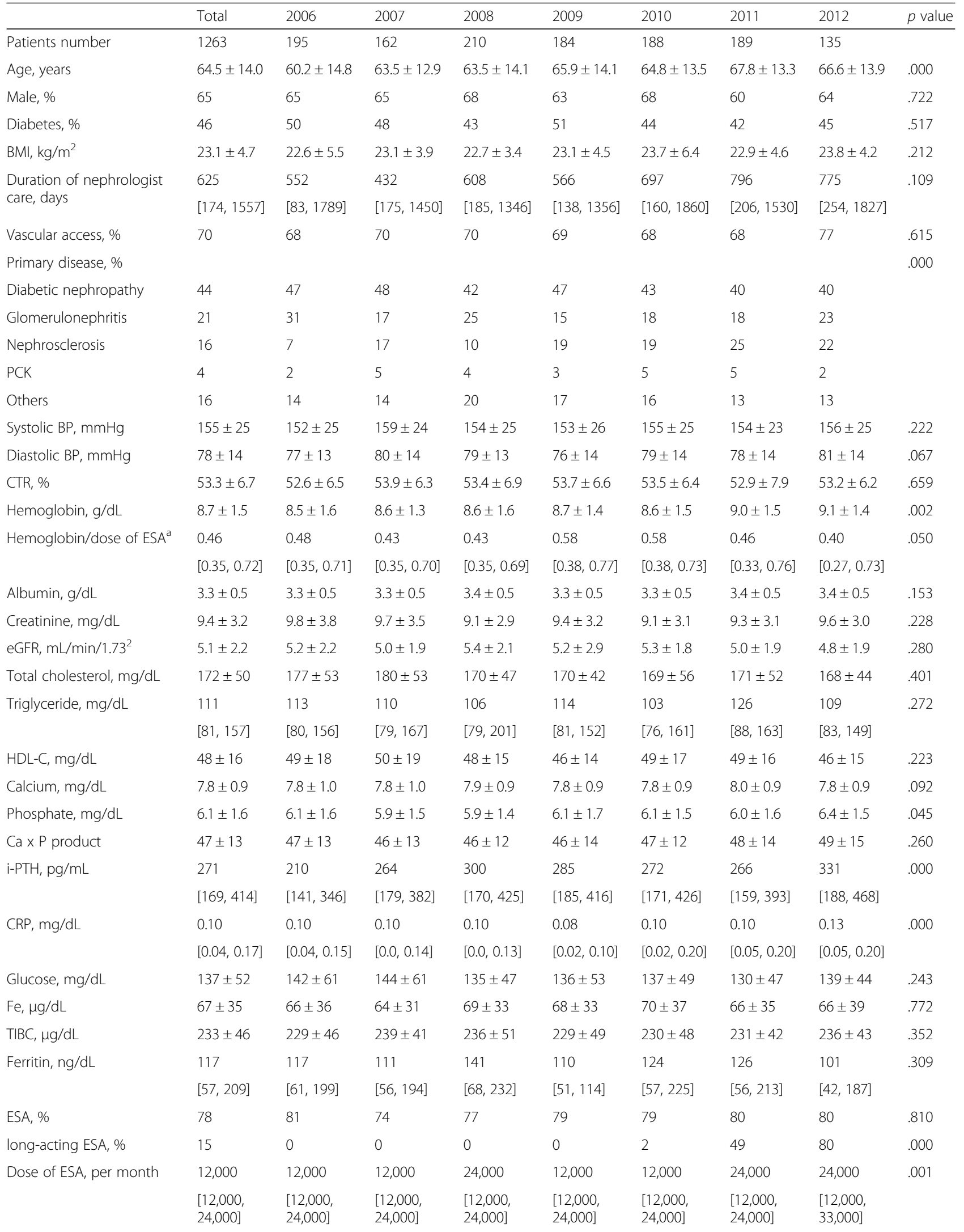


Table 1 The characteristics of the study patients and temporal trends for 7 years (Continued)

\begin{tabular}{llllllllll}
\hline ARB/ACE-I, \% & 64 & 56 & 67 & 69 & 61 & 70 & 65 & 61 & .051 \\
Vitamin D, \% & 31 & 26 & 34 & 271 & 23 & 36 & 32 & 41 & .007 \\
AST-120, \% & 19 & 17 & 18 & 27 & 19 & 19 & 16 & 14 & 0.054 \\
Iron, \% & 19 & 31 & 18 & 20 & 18 & 14 & 23 & 19 & .403 \\
\hline
\end{tabular}

Data are expressed as the mean $\pm S D$, median [interquartile range], or percentage

$B M I$ body mass index, $P C K$ polycystic kidney disease, $B P$ blood pressure, CTR cardiothoracic ratio, eGFR estimated glomerular filtration rate, HDL-C high density lipoprotein, $i-P T H$ intact parathyroid hormone, $C R P C$-reactive protein, $T I B C$ total iron-binding capacity, ESA erythropoiesis-stimulating agents, ARB angiotensin receptor blocker, $A C E-I$ angiotensin-converting enzyme inhibitor

${ }^{\mathrm{a}}$ Hemoglobin was corrected by dose of ESA per 1000units

association of various factors with $\mathrm{Hb}$ level, Spearman univariate regression analysis was employed. Dummy variables were used for gender ( 0 for female, 1 for male), primary renal disease ( 0 for non-diabetic nephropathy, 1 for diabetic nephropathy), smoking history ( 0 for negative, 1 for positive), and each medication ( 0 for not used, 1 for used). Dummy variables were also used for type of ESA (0 for short-acting ESA, 1 for long-acting ESA). The monthly ESA dose was evaluated as a numerical factor. The dose was also divided by 1000 units for analysis as appropriate. Multivariate regression analysis was also performed to identify independent determinants of $\mathrm{Hb}$ concentration. In all analyses, a probability $(P)$ value $<0.05$ was considered statistically significant. All statistical analyses were performed using SPSS for Windows version 20 (IBM, New York, USA).

\section{Results}

\section{Patient characteristics}

The mean age of the entire group of study subjects was $64.5 \pm 14.0$ years. The percentage of men $(64.6 \%)$ and the percentage of patients with diabetic nephropathy (43.8\%) were similar to the percentages previously reported at the initiation of dialysis for the entire Japanese dialysis population [17]. The mean serum creatinine (Cr) and eGFR at the initiation of renal replacement therapy (RRT) were $9.5 \pm$ $3.3 \mathrm{mg} / \mathrm{dL}$ and $5.2 \pm 2.2 \mathrm{~mL} / \mathrm{min} / 1.73 \mathrm{~m}^{2}$, respectively, which were similar to the levels for the Japanese dialysis population [17]. Therefore, our subjects seemed to constitute a suitable sample of Japanese dialysis patients. The mean $\mathrm{Hb}$ level was $8.8 \pm 1.5 \mathrm{~g} / \mathrm{dL}$, and the median monthly estimated dose of epoetin just before the initiation of $\mathrm{HD}$ was 12,000 units per month. Other clinical characteristics are shown in the first column of Table 1.

\section{Yearly trend of patient characteristics}

We examined changes in the clinical features of the study patients during the study period (2006-2012). Age increased over time from 60 to 67 years $(P<0.001$ for trend). The $\mathrm{Hb}$ level dramatically increased over time $(P<0.001$ for trend) from 8.6 to $9.1 \mathrm{~g} / \mathrm{dL}$. In particular, as shown in Fig. 1, the rise in the $\mathrm{Hb}$ level was confirmed during 2011 and 2012, along with a significant and parallel increase in the proportion of usage of longacting ESAs (Fig. 2). The concentrations of iron, total iron-binding capacity (TIBC), and ferritin did not show any significant changes during the 7-year study period. The ratio of iron medicine users increased during the last 2 years, in 2011 and 2012.

\section{Differences in $\mathrm{Hb}$ level and clinical characteristics between ESA types}

The comparison of the $\mathrm{Hb}$ level between the three patient groups (long-acting ESA users, short-acting ESA users, and non-ESA users) is shown in Fig. 3. The $\mathrm{Hb}$ level of the patients in the long-acting ESA group was significantly higher than the $\mathrm{Hb}$ levels of the shortacting ESA group and the non-ESA group. No significant difference was observed between the non-ESA users and the short-acting ESA users. The other clinical characteristics in three patient groups are shown in Table 2 . Some tendencies between three patient groups are seen in the Table. Older, longer duration of nephrologist care, higher albumin level, lower eGFR, and higher usage of vitamin D were found in ESKD patients with long-acting ESA compared with those of the other two groups.

\section{Univariate regression analysis determined the factors associated with $\mathrm{Hb}$}

Among the clinical characteristics, planned vascular access, serum albumin, eGFR, total cholesterol, Ca, TIBC, long-acting ESA use, and estimated long-acting ESA dose were significantly correlated with $\mathrm{Hb}$ level, as shown in Table 3. Significant negative associations were observed between $\mathrm{Hb}$ and CTR and serum phosphate level.

\section{Independent association of long-acting ESA with $\mathrm{Hb}$}

Table 4 presents the independent association of longacting ESA use and its estimated dose with Hb. Dummy variables were used for type of ESA ( 0 for short-acting ESA, 1 for long-acting ESA). The positive association of long-acting ESA use with $\mathrm{Hb}$ remained significant after adjustment for age, gender, diabetes, BMI, systolic BP, vascular access, duration of nephrologist care, CTR, and estimated long-acting ESA dose as shown in model 2. This was true even after further adjustment for markers 


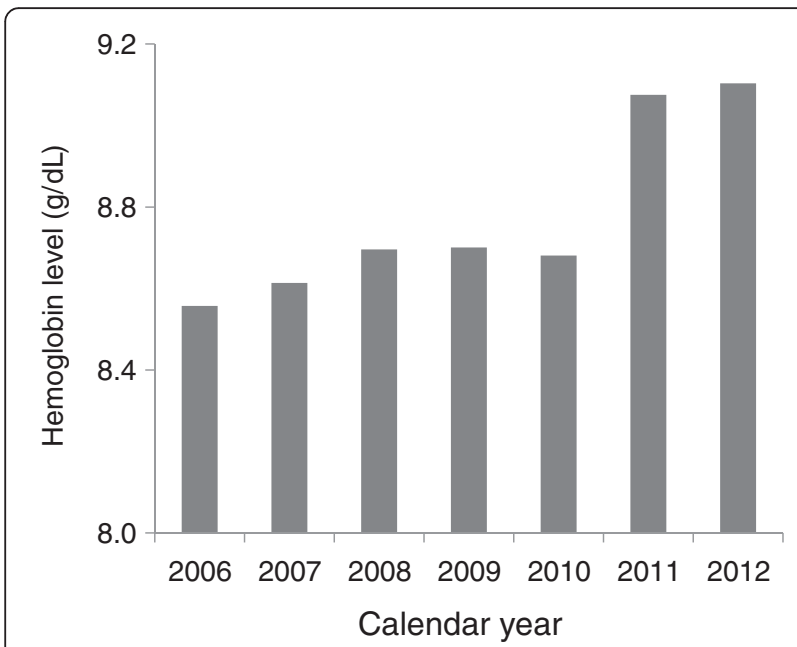

Fig. 1 The concentration of $\mathrm{Hb}$ dramatically increased over time $(P<0.001$ for trend) from 8.6 to $9.1 \mathrm{~g} / \mathrm{dL}$ in the 7-year study period. The remarkable increase in $\mathrm{Hb}$ level was confirmed between 2010 and 2011, along with a significant and parallel increase in the proportion of use of long-acting ESA

of malnutrition and inflammation (albumin and CRP), markers of lipid and glucose metabolism (total cholesterol, triglycerides, high-density lipoprotein (HDL)-C, and glucose), markers of calcium phosphate metabolism (calcium, phosphate, intact parathyroid hormone, use of vitamin $\mathrm{D}$ ), markers for iron metabolism (Fe, TIBC, ferritin, use of iron agent), and medications (use of ACE-I/ ARB, AST-120) as shown in models 3 through 7. Finally, as shown in model 8, the independent association of long-acting ESA with $\mathrm{Hb}$ was confirmed by multiple linear regression analysis, including all markers of models

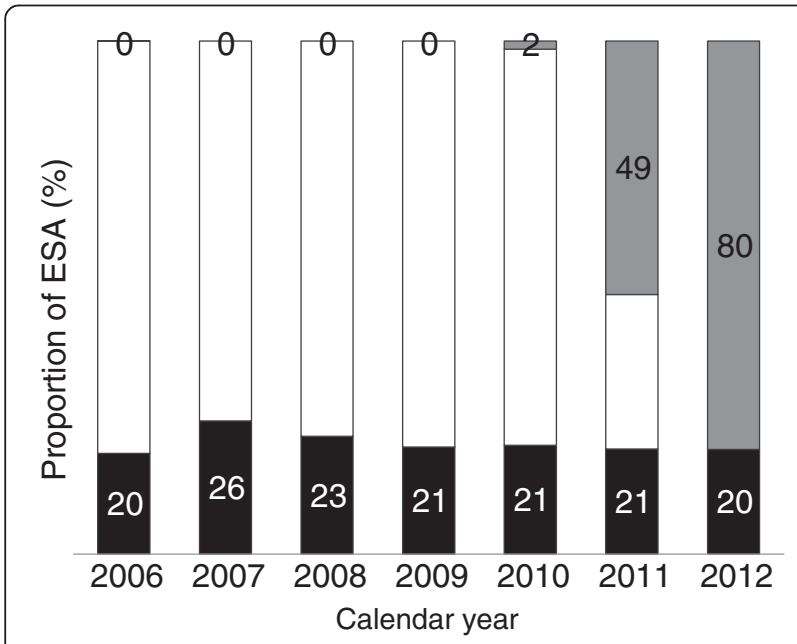

Fig. 2 The grouped bar graph depicts the yearly trend of the proportion of ESA. The use of long-acting ESA (gray bar) significantly increased in last 2 years of the study, 2011 and $2012(P<0.001$ for trend). About $20 \%$ of the patients did not use ESA (black bar) in any calendar year. White bar means percentage of patients with short-acting ESA

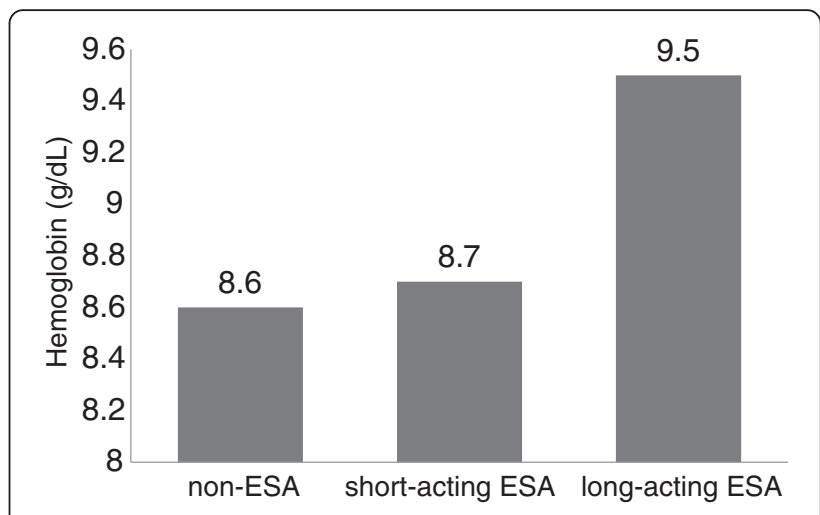

Fig. 3 The $\mathrm{Hb}$ level of patients who received long-acting ESA was significantly higher than in the patients who received no ESA $(P<0.001)$ or short-acting ESA $(P<0.001)$. There was no significant difference in $\mathrm{Hb}$ levels between the non-ESA and short-acting ESA patient groups

2 to 7 . On the other hand, no significant associations of $\mathrm{Hb}$ level with estimated long-acting ESA dose were observed in all models of multiple linear regression analysis including long-acting ESA use.

\section{Association of long-acting ESA with categorical Hb levels}

For real world clinical implication, multiple logistic regression analysis was performed to identify the association of long-acting ESA with categorical $\mathrm{Hb}$ levels by using dummy variables, 0 for short-acting ESA, 1 for long-acting ESA. As shown in Table 5, higher level of categorical $\mathrm{Hb}$ level was more associated with the use of long-acting ESA compared with reference category of Hb 8.0-8.9 after adjusted by age, sex, BMI, diabetes, albumin, eGFR, and CRP. No significant associations were observed between categorical $\mathrm{Hb}$ level less than 8.0 and use of long-acting ESA.

\section{Discussion}

Main findings of current study

Based on the registry data of Japanese dialysis patients from nine hospitals, the mean $\mathrm{Hb}$ level at the initiation of dialysis is $8.5 \mathrm{~g} / \mathrm{dL}$, which is much lower than the optimal $\mathrm{Hb}$ level recommended by international guidelines [6-8]. It remains unclear whether the change of ESA type has exerted an advantageous effect on the $\mathrm{Hb}$ level at the initiation of maintenance dialysis. Our present multicenter study clearly showed three important findings: (1) $\mathrm{Hb}$ level at the initiation of dialysis has dramatically increased in the past 2 years (2011 and 2012) compared with the Hb levels from 2006 to 2010; (2) parallel with this trend, the main type of ESA used has drastically changed from short-acting such as epoetin $\alpha / \beta$ to long-acting such as darbepoetin- $\alpha$ and CERA between 2010 and 2011; and (3) the use of long-acting ESA was strongly and independently associated with $\mathrm{Hb}$ level in our study subjects. These findings suggest that long- 
Table 2 The characteristics of 3 patient groups, non-ESA, ESA-short, and ESA-long

\begin{tabular}{|c|c|c|c|c|}
\hline & Non-ESA & Short-acting ESA & Long-acting ESA & $p$ value \\
\hline Patients number & 271 & 788 & 204 & \\
\hline Age, years & $63.8 \pm 14.9$ & $64.2 \pm 13.7$ & $67.0 \pm 13.9$ & .021 \\
\hline Male, \% & 66 & 65 & 61 & .546 \\
\hline Diabetes, \% & 47 & 47 & 44 & .800 \\
\hline $\mathrm{BMl}, \mathrm{kg} / \mathrm{m}^{2}$ & $22.3 \pm 5.8$ & $23.3 \pm 4.5$ & $23.3 \pm 4.0$ & .016 \\
\hline Duration of nephrologist care, days & $117[5,923]$ & $715[281,1723]$ & $872[307,1748]$ & .000 \\
\hline Vascular access, \% & 46 & 74 & 86 & .000 \\
\hline Diabetic nephropathy & 44 & 45 & 39 & .404 \\
\hline Systolic BP, mmHg & $158 \pm 25$ & $154 \pm 25$ & $154 \pm 25$ & .070 \\
\hline Diastolic BP, mmHg & $82 \pm 15$ & $78 \pm 14$ & $80 \pm 15$ & .000 \\
\hline CTR, \% & $55 \pm 8$ & $53 \pm 6$ & $53 \pm 6$ & .002 \\
\hline Hemoglobin, g/dL & $8.6 \pm 1.6$ & $8.7 \pm 1.5$ & $9.5 \pm 1.4$ & .000 \\
\hline Hemoglobin/dose of ESA & - & $0.51[0.36,0.73]$ & $0.40[0.28,0.72]$ & .000 \\
\hline Albumin, g/dL & $3.3 \pm 0.6$ & $3.4 \pm 0.6$ & $3.5 \pm 0.5$ & .002 \\
\hline Creatinine, $\mathrm{mg} / \mathrm{dL}$ & $8.9 \pm 3.4$ & $9.6 \pm 3.3$ & $9.6 \pm 3.1$ & .012 \\
\hline $\mathrm{eGFR}, \mathrm{mL} / \mathrm{min} / 1.73^{2}$ & $5.7 \pm 3.0$ & $5.1 \pm 1.9$ & $4.9 \pm 2.0$ & .000 \\
\hline Total cholesterol, mg/dL & $186 \pm 64$ & $172 \pm 47$ & $162 \pm 44$ & .000 \\
\hline Triglyceride, mg/dL & $122[84,182]$ & $109[78,154]$ & $110[83,150]$ & .082 \\
\hline $\mathrm{HDL}-\mathrm{C}, \mathrm{mg} / \mathrm{dL}$ & $50 \pm 19$ & $49 \pm 17$ & $47 \pm 16$ & .473 \\
\hline Calcium, mg/dL & $7.8 \pm 1.1$ & $7.9 \pm 1.0$ & $8.0 \pm 1.0$ & .013 \\
\hline Phosphate, mg/dL & $6.3 \pm 1.8$ & $6.0 \pm 1.5$ & $6.3 \pm 1.6$ & .010 \\
\hline Ca $\times$ P product & $47 \pm 16$ & $47 \pm 12$ & $49 \pm 15$ & .067 \\
\hline i-PTH, pg/mL & $291[171,421]$ & $265[168,403]$ & $291[168,446]$ & .176 \\
\hline $\mathrm{CRP}, \mathrm{mg} / \mathrm{dL}$ & $0.10[0.05,0.17]$ & $0.10[0.02,0.13]$ & $0.14[0.04,0.20]$ & .000 \\
\hline glucose, mg/dL & $132 \pm 55$ & $140 \pm 52$ & $138 \pm 50$ & .156 \\
\hline $\mathrm{Fe}, \mu \mathrm{g} / \mathrm{dL}$ & $72 \pm 36$ & $67 \pm 34$ & $65 \pm 38$ & .167 \\
\hline $\mathrm{TIBC}, \mu \mathrm{g} / \mathrm{dL}$ & $231 \pm 56$ & $233 \pm 45$ & $236 \pm 43$ & .644 \\
\hline Ferritin, ng/dL & $140[73,282]$ & $117[57,204]$ & $105[49,193]$ & .077 \\
\hline Dose of ESA, per month & 0 & $12,000[12,000,24,000]$ & $24,000[12,000,36,000]$ & .000 \\
\hline ARB/ACE-I, \% & 56 & 67 & 65 & .003 \\
\hline Vitamin D, \% & 21 & 31 & 44 & .000 \\
\hline AST-120, \% & 9 & 22 & 18 & .000 \\
\hline Iron, \% & 10 & 21 & 23 & .001 \\
\hline
\end{tabular}

Data are expressed as the mean $\pm S D$, median [interquartile range], or percentage

$B M I$ body mass index, $B P$ blood pressure, $C T R$ cardiothoracic ratio, eGFR estimated glomerular filtration rate, $H D L-C$ high density lipoprotein, $i-P T H$ intact parathyroid hormone, $C R P$ c-reactive protein, $T I B C$ total iron-binding capacity, ESA erythropoiesis-stimulating agents, $A R B$ angiotensin receptor blocker, $A C E-I$ angiotensin-converting enzyme inhibitor

${ }^{\mathrm{a}}$ Hemoglobin was corrected by dose of ESA per 1000units

acting ESAs (darbepoetin- $\alpha$ and CERAs) could help $\mathrm{CKD}$ patients maintain their $\mathrm{Hb}$ near the optimal level even in a severely uremic state, which is one of the strongest causes of ESA-resistant anemia.

\section{Assessment of the effects of long-acting ESA on Hb level}

The ability to use a higher dosage of epoetin could explain the beneficial effect of long-acting ESA on $\mathrm{Hb}$. Based on the instructions for the use of long-acting ESA in the drug package insert, and referring to the recommended dose conversion ratio from darbepoetin or CERA to epoetin $[15,16]$, we can theoretically prescribe an approximately 1.5 times higher monthly estimated dose of epoetin in the predialytic phase of CKD. In Japan, max monthly dosage of epoetin- $\alpha$ or $-\beta$ is 24,000 IU in predialytic phase of CKD patients. For darbepoetin- $\alpha$ and CERA, max monthly dosages are 240 and $250 \mu \mathrm{g}$, respectively. Based on the dose conversion 
Table 3 Univariate linear regression analysis for the factors associated with $\mathrm{Hb}$ level

\begin{tabular}{|c|c|c|c|c|}
\hline & Regression coefficient & $95 \% \mathrm{Cl}$ & & $P$ \\
\hline Age, years & .036 & 0.002 & .010 & .195 \\
\hline Male & .047 & 0.023 & .320 & .089 \\
\hline Diabetes & .059 & .014 & .343 & .033 \\
\hline BMI & .018 & 0.024 & .012 & .524 \\
\hline Duration of nephrologist care & .013 & .000 & .000 & .655 \\
\hline Vascular access & .151 & .320 & .674 & .000 \\
\hline Diabetic nephropathy & .026 & 0.112 & .039 & .339 \\
\hline Systolic BP & .014 & 0.004 & .002 & .622 \\
\hline Diastolic BP & .048 & 0.001 & .011 & .090 \\
\hline CTR & .157 & 0.05 & 0.022 & .000 \\
\hline Albumin & .176 & .330 & .619 & .000 \\
\hline Creatinine & .162 & 0.1 & 0.05 & .278 \\
\hline eGFR & .187 & .090 & .163 & .000 \\
\hline Total cholesterol & .11 & .001 & .005 & .000 \\
\hline Triglyceride & .074 & .000 & .003 & .013 \\
\hline $\mathrm{HDL}-\mathrm{C}$ & .040 & 0.002 & .009 & .188 \\
\hline Calcium & .201 & .223 & .383 & .000 \\
\hline Phosphate & .088 & 0.134 & 0.032 & .001 \\
\hline Ca $\times$ P product & .020 & 0.004 & .008 & .467 \\
\hline i-PTH & .049 & 0.001 & .000 & .113 \\
\hline C-reactive protein & .002 & 1.087 & 1.016 & .948 \\
\hline Glucose & .016 & 0.001 & .002 & .585 \\
\hline $\mathrm{Fe}$ & .068 & .000 & .005 & .021 \\
\hline TIBC & .087 & .001 & .005 & .003 \\
\hline Ferritin & .074 & 0.001 & .000 & .013 \\
\hline$E S A^{a}$ & .031 & .079 & .285 & .268 \\
\hline Long-acting $E S A^{b}$ & .205 & 0.524 & 0.967 & .000 \\
\hline Dose of ESA, per 1000 units & .075 & .002 & .019 & .015 \\
\hline ARB/ACE-I & .019 & 0.113 & .233 & .497 \\
\hline Vitamin D & .020 & 0.12 & 0.253 & .484 \\
\hline AST-120 & .017 & 0.148 & .275 & .554 \\
\hline Iron & .000 & 0.176 & .176 & .999 \\
\hline
\end{tabular}

$B M I$ body mass index, $B P$ blood pressure, $C T R$ cardiothoracic ratio, eGFR estimated glomerular filtration rate, $H D L-C$ high density lipoprotein, $i-P T H$ intact parathyroid hormone, CRP c-reactive protein, TIBC total iron-binding capacity, ESA erythropoiesis-stimulating agents, $A R B$ angiotensin receptor blocker, $A C E-I$ angiotensin-converting enzyme inhibitor

${ }^{a}$ Dummy variables was used for usage of any type of ESA ( 0 for not used, 1 for used)

${ }^{\mathrm{b}}$ Dummy variables was used for type of ESA (0 for short-acting ESA, 1 for long-acting ESA)

ratio to epoetin 200:1 for darbepoetin and 270:1 for CERA, at least one-half dosage of estimated epoetin was applicable to CKD patients. Indeed, as shown in Table 1, an estimated dose of epoetin 1.5 times higher was administered to the patients after 2011 compared with before 2010. It is thought that the switch from a short-acting to a long-acting ESA increases the available estimated dose of epoetin, and consequently, the $\mathrm{Hb}$ level at the initiation of dialysis.
Iron status is one of the important parts for the optimal treatment of anemia in ESKD patients. The difference of iron utilization could play some role more increasing of $\mathrm{Hb}$ level in patients with long-acting ESA than those of short-acting ESA. Actually, it is reported that difference of type of ESA [18] or difference of administration interval of ESA [19] make a changing of iron status favorably for treatment of anemia in ESKD patients. However, any remarkable differences did not 
Table 4 Independent association of use and dose of long-acting ESA with Hb level by multiple linear regression analysis

\begin{tabular}{|c|c|c|c|c|c|c|}
\hline \multirow{2}{*}{$\frac{\text { Model }}{\text { Model } 1^{\text {a }}}$} & \multirow{2}{*}{$\begin{array}{l}\text { Adjustment } \\
\text { Unadjusted }\end{array}$} & \multirow[b]{2}{*}{ Long-acting ESA } & \multirow{2}{*}{$\frac{\text { Regression coefficient }}{0.204}$} & \multicolumn{2}{|l|}{$95 \% \mathrm{Cl}$} & \multirow{2}{*}{$\frac{P}{.000}$} \\
\hline & & & & 0.515 & 1.02 & \\
\hline & & Dose of ESA/1000 units & 0.024 & 0.007 & 0.014 & .483 \\
\hline \multirow[t]{2}{*}{ Model $2^{b}$} & Age, sex, diabetes, BMI, SBP, vascular access, nephrologists care, CTR & Long-acting ESA & 0.191 & 0.427 & 0.976 & .000 \\
\hline & & Dose of ESA/1000 units & 0.019 & 0.014 & 0.008 & .613 \\
\hline \multirow[t]{2}{*}{ Model $3^{c}$} & Model $2+$ albumin, CRP & Long-acting ESA & 0.169 & 0.341 & 0.912 & .000 \\
\hline & & Dose of ESA/1000 units & 0.013 & 0.013 & 0.009 & .721 \\
\hline \multirow[t]{2}{*}{ Model $4^{d}$} & Model $2+$ TC, TG,HDL-C, Glu & Long-acting ESA & 0.196 & 0.41 & 1.039 & .000 \\
\hline & & Dose of ESA/1000 units & 0.023 & 0.017 & 0.01 & .588 \\
\hline \multirow[t]{2}{*}{ Model $5^{e}$} & Model $2+C a, P$, iPTH, vitamin D & long-acting ESA & 0.186 & 0.388 & 0.948 & .000 \\
\hline & & Dose of ESA/1000 units & 0.022 & 0.015 & 0.008 & .570 \\
\hline \multirow[t]{2}{*}{ Model $6^{f}$} & Model $2+\mathrm{Fe}$, TIBC, ferritin, iron tx & Long-acting ESA & 0.168 & 0.275 & 0.848 & .000 \\
\hline & & Dose of ESA/1000 units & 0.029 & 0.018 & 0.009 & .503 \\
\hline \multirow[t]{2}{*}{ Model $7^{\mathrm{g}}$} & Model $2+$ ACEI/ARB, AST-120 & Long-acting ESA & 0.188 & 0.411 & 0.962 & .000 \\
\hline & & Dose of ESA/1000 units & 0.016 & 0.014 & 0.009 & .683 \\
\hline \multirow[t]{2}{*}{ Model $8^{h}$} & All & Long-acting ESA & 0.155 & 0.176 & 0.858 & .003 \\
\hline & & Dose of ESA/1000 units & 0.029 & 0.019 & 0.01 & .555 \\
\hline
\end{tabular}

\section{anadjusted}

${ }^{\mathrm{b}}$ Adjusted for age, sex, diabetes nephropathy, BMI, SBP, vascular access, duration of nephrologists care, and CTR

${ }^{\mathrm{C}}$ Adjusted for variables in model 2 plus albumin and CRP

${ }^{\mathrm{d}}$ Adjusted for variables in model 2 plus total cholesterol, triglyceride, high lipoprotein cholesterol, and glucose

${ }^{\text {e}}$ Adjusted for variables in model 2 plus calcium, phosphate, and intact-PTH

${ }^{f}$ Adjusted for variables in model 2 plus Fe, TIBC, ferritin, and usage of iron medication

${ }_{9}^{9}$ Adjusted for variables in model 2 plus usage of angiotensin-converting enzyme inhibitors, angiotensin-II receptor blockers, and AST-120

${ }^{\mathrm{h}}$ Adjusted for all variables from model 2 to 7

exist between two patients group with long-acting ESA and short-acting ESA in the marker of iron status such as iron, ferritin, TSAT, and usage of iron agents. Therefore, it is not likely that the status and utilization of iron play some role for increasing $\mathrm{Hb}$ level in long-acting ESA in this study.

Another possibility is that, independent of dose, the potential direct effect of a long-acting ESA could play a role in the elevation of $\mathrm{Hb}$ level at the initiation of dialysis. On multiple regression analysis, use of long-acting ESA was more closely associated with $\mathrm{Hb}$ level than its estimated dose from the conversion ratio in our study. Several studies have suggested that the conversion ratio from epoetin to darbepoetin- $\alpha$ of $1: 350$ in the clinical

Table 5 Independent association of categorical $\mathrm{Hb}$ level with using of long-acting ESA ${ }^{a}$

\begin{tabular}{llll}
\hline Hemoglobin, $\mathrm{g} / \mathrm{dL}$ & Odds ratio & $95 \% \mathrm{Cl}$ & $p$ \\
\hline$<7.0$ & 0.673 & $0.302-1.502$ & .334 \\
$7.0-7.9$ & 0.858 & $0.476-1.548$ & .611 \\
$8.0-8.9$ & 1 & & \\
$9.0-9.9$ & 2.218 & $1.349-3.646$ & .002 \\
$10.0-10.9$ & 2.844 & $1.652-4.896$ & .000 \\
$\geq 11.0$ & 3.102 & $1.596-6.031$ & .001 \\
\hline
\end{tabular}

${ }^{\mathrm{a}}$ Adjusted by age, sex, BMI, diabetes, albumin, eGFR, and CRP setting is higher than the fundamental conversion ratio from the molecular structure of 1:200 [15, 20]. This might mean that darbepoetin- $\alpha$ has a potentially more powerful effect on increasing the $\mathrm{Hb}$ than we expected. Further study is needed to prove this issue.

Many clinical factors are thought to affect the Hb level at the initiation of dialysis. Residual renal function is thought to be the biggest contributor to $\mathrm{Hb}$ levels in CKD patients. It is well known that a positive relationship exists between endogenous erythropoietin concentration and the serum eGFR [21] in CKD patients. The present study was conducted by using a combined database from nine hospitals. The question arises of whether the policy and indication for starting dialysis are not standardized, but rather, are at each physician's discretion. This could make a difference in the timing for starting dialysis, and, consequently, influence the $\mathrm{Hb}$ concentration at the initiation of dialysis. Therefore, in order to minimize this bias, multivariate regression analysis was performed to adjust for confounding variables, including renal function. After adjusting by serum creatinine level or eGFR, the positive association of long-acting ESA with $\mathrm{Hb}$ level remained statistically significant. Also, after simultaneously adjusting for other factors, as seen in Tables 4 and 5, the use of long-acting ESA was well-associated with $\mathrm{Hb}$ concentration. These findings imply that long-acting ESA plays a 
beneficial role in maintaining a higher $\mathrm{Hb}$ concentration than short-acting ESA. The reason is probably the higher estimated epoetin dose or other potential effect. We would like to emphasize that excluding the patients with suspicion of low responsiveness to ESA could lead an anticipating results.

\section{Limitations}

A major limitation of the present study was the study design. A cross-sectional study design cannot be used to prove clear any causal effect of ESA on $\mathrm{Hb}$ level. The data available to us concerning ESA covered only the dosage in the month immediately before the initiation of dialysis. No information about the duration of ESA treatment existed in our database. To minimize such bias, we attempted to perform multivariate analysis including the factors "Duration of nephrologist care before initiation of dialysis" and "vascular access." These two factors may be markers of CKD patients' adaptation to dialysis, the patients' compliance with their nephrologists' care plans, and the degree of patient education received by the patients. After adjusting for these two markers, the association of long-acting ESA with $\mathrm{Hb}$ remained statistically significant. These results suggest that long-acting ESA could increase the $\mathrm{Hb}$ level in the advanced stages of CKD even in a relatively short duration of treatment. Another limitation of the present study is that the target $\mathrm{Hb}$ level may be not consistent among doctors or hospitals. However, we do have confirmed with all the members of J-START that management of anemia in the predialytic phase was performed essentially based on the Japanese guidelines published in 2004 and 2008 [8, 22]. Especially, from 2008, we changed the management of anemia to a protocol based on the Japanese guidelines [8]. The target $\mathrm{Hb}$ levels for non-dialyzed patients were almost the same in both guidelines from 11 to $12 \mathrm{~g} / \mathrm{dL}$. Third, we have a look at the trend for decreasing of percentage of diabetic nephropathy, which is different from those of western countries. This difference could make an advantage to our finding. However, even including diabetic nephropathy in multivariate analysis, our main finding that the positive association of long-acting ESA use with $\mathrm{Hb}$ was observed remained significant. Therefore, we believe that the bias has no big influence to our results. Fourth, about $50 \%$ of ESKD patients showed CRP level over $0.3 \mathrm{mg} / \mathrm{dL}$ and were excluded from our study. As we described in the method area, blood sample data in this study was collected just before the first HD session. Advanced uremic state can lead to non-infected chronic inflamed state. Also, uremic state would be the cause of immune dysfunction consequently susceptible to infectious disease. Based on these assessments, it is reasonable to find that about $50 \%$ of ESKD patients at the initiation of dialysis showed CRP level over $0.3 \mathrm{mg} / \mathrm{dL}$ on the blood sampling just before the first HD session. Actually, DOPPS study [23] demonstrated that median CRP level of 1392 Japanese stable chronic hemodialysis patients is $0.1 \mathrm{mg} / \mathrm{dL}$ with interquartile range from 0.05 to $0.31 \mathrm{mg} / \mathrm{dL}$. This means that about $25 \%$ of patients showed CRP level over $0.3 \mathrm{mg} / \mathrm{dL}$ even in stable dialysis patients.

\section{Conclusions}

The use of long-acting ESAs such as darbepoetin- $\alpha$ and CERA elevates the Hb level in the advanced stages of CKD. This effect might be mainly due to the ability to use a higher estimated dose of epoetin. However, the cross-sectional design of the present study does not offer proof of the causal effect of long-acting ESA on $\mathrm{Hb}$ at the initiation of dialysis. It is therefore essential to begin a longitudinal study to prove this potential beneficial effect of ameliorating anemia in CKD patients.

\section{Competing interests}

I declare that the authors have no conflict of interest in connection with this paper.

\section{Authors' contributions}

This manuscript has not been published and is not under consideration for publication elsewhere. All the authors have read the manuscript and have approved this submission.

\section{Acknowledgements}

The authors gratefully acknowledge Hiroyuki Sekihara, Moriaki Osaka, Hiroyuki Miyakawa, Hiromi Okamoto, Kazuhiko Kitano, and Ryoji Kijima for the management of the J-START database.

\section{Financial support \\ None.}

\section{Author details}

1Division of Nephrology, Toho University Ohashi Medical Center, 2-17-6 Ohashi, Meguro-ku, Tokyo 153-8515, Japan. ${ }^{2}$ Division of Nephrology and Hypertension, The Jikei University Katsushika Medical Center, Tokyo, Japan. ${ }^{3}$ Department of Nephrology, Musashino Red Cross Hospital, Tokyo, Japan. ${ }^{4}$ Dialysis Center, Kawakita General Hospital, Tokyo, Japan. ${ }^{5}$ Kidney Center, Nagoya Daini Red Cross Hospital, Nagoya, Japan. ${ }^{6}$ Division of Nephrology, Department of Internal Medicine, Wakayama Medical University, Wakayama, Japan. ${ }^{7}$ Department of Nephrology, Division of Internal Medicine, St. Luke's International Hospital, Tokyo, Japan. ${ }^{8}$ Division of Nephrology, Department of Internal Medicine, Showa University Fujigaoka Hospital, Yokohama, Japan.

${ }^{9}$ Department of Clinical Engineering, Social Insurance Chuo General Hospital, Tokyo, Japan. ${ }^{10}$ Department of Nephrology, Rinku General Hospital, Osaka, Japan.

Received: 25 June 2015 Accepted: 2 November 2015

Published online: 22 February 2016

\section{References}

1. Silva RP, Barbosa PH, Kimura OS, Sobrinho CR, Sousa Neto JD, Silva FA, et al. Prevalance of anemia and its association with cardio-renal syndrome. Int J Cardiol. 2007;120:232-6.

2. Foley RN, Parfrey PS, Morgan J, Barre PE, Campbell P, Cartier P, et al. Effect of hemoglobin levels in hemodialysis patients with asymptomatic cardiomyopathy. Kidney Int. 2000;58:1325-35.

3. de Francisco AL, Pinera C. Anemia trials in CKD and clinical practice: refining the approach to erythropoiesis-stimulating agents. Contrib Nephrol. 2011; 171:248-54

4. Akizawa $T$, Makino $H$, Matsuo $S$, Watanabe $T$, Imai $E$, Nitta $K$, et al. Management of anemia in chronic kidney disease patients: baseline 
findings from Chronic Kidney Disease Japan Cohort Study. Clin Exp Nephrol. 2011;15:248-57.

5. Tanaka Y, Joki N, Hase H, Iwasaki M, Ikeda M, Ando R, et al. Effect of erythropoietin-stimulating agent on uremic inflammation. J Inflamm (Lond). 2012;9:17.

6. Drueke TB, Parfrey PS. Summary of the KDIGO guideline on anemia and comment: reading between the (guide)line(s). Kidney Int. 2012;82:952-60.

7. KDOQI. Clinical Practice Guideline and Clinical Practice Recommendations for anemia in chronic kidney disease: 2007 update of hemoglobin target. Am J Kidney Dis. 2007;2007(50):471-530.

8. Tsubakihara Y, Nishi S, Akiba T, Hirakata H, Iseki K, Kubota M, et al. Japanese Society for Dialysis Therapy: guidelines for renal anemia in chronic kidney disease. Ther Apher Dial. 2008;2010(14):240-75.

9. Go AS, Chertow GM, Fan D, McCulloch CE, Hsu CY. Chronic kidney disease and the risks of death, cardiovascular events, and hospitalization. New Engl J Med. 2004;351:1296-305.

10. Anavekar NS, McMurray JJ, Velazquez EJ, Solomon SD, Kober L, Rouleau JL, et al. Relation between renal dysfunction and cardiovascular outcomes after myocardial infarction. New Engl J Med. 2004;351:1285-95.

11. Horowitz J, Agarwal A, Huang F, Gitlin M, Gandra SR, Cangialose CB. Empirical methods to calculate an erythropoiesis-stimulating agent dose conversion ratio in nondialyzed patients with chronic kidney disease. J Manag Care Pharm. 2009;15:741-50.

12. Matsuo S, Imai E, Horio M, Yasuda Y, Tomita K, Nitta K, et al. Revised equations for estimated GFR from serum creatinine in Japan. Am J Kidney Dis. 2009:53:982-92.

13. Taki K, Niwa T. Indoxyl sulfate-lowering capacity of oral sorbents affects the prognosis of kidney function and oxidative stress in chronic kidney disease. J Ren Nutr. 2007;17:48-52.

14. Shimoishi K, Anraku M, Kitamura K, Tasaki Y, Taguchi K, Hashimoto M, et al. An oral adsorbent, AST-120 protects against the progression of oxidative stress by reducing the accumulation of indoxyl sulfate in the systemic circulation in renal failure. Pharm Res. 2007;24:1283-9.

15. Bock HA, Hirt-Minkowski P, Brunisholz M, Keusch G, Rey S, von Albertini B. Darbepoetin alpha in lower-than-equimolar doses maintains haemoglobin levels in stable haemodialysis patients converting from epoetin alpha/beta. Nephrol Dial Transplant. 2008;23:301-8.

16. Sulowicz W, Locatelli F, Ryckelynck JP, Balla J, Csiky B, Harris K, et al. Oncemonthly subcutaneous C.E.R.A. maintains stable hemoglobin control in patients with chronic kidney disease on dialysis and converted directly from epoetin one to three times weekly. Clin J Am Soc Nephrol. 2007;2:637-46.

17. Nakai S, Iseki K, Itami N, Ogata S, Kazama JJ, Kimata N, et al. An overview of regular dialysis treatment in Japan (as of 31 December 2010). Ther Apher Dial. 2012;16:483-521.

18. Jonckheere S, Dierick J, Vanhouteghem H, Devleeschouwer M, Stove V. Erythrocyte indices in the assessment of iron status in dialysis-dependent patients with end-stage renal disease on continuous erythropoietin receptor activator versus epoetin beta therapy. Acta Haematol. 2010;124:27-33.

19. Morikami Y, Fujimori A, Okada S, Kumei M, Mizobuchi N, Sakai M. Comparison of 2-week versus 4-week dosing intervals of epoetin beta pegol on erythropoiesis and iron metabolism in hemodialysis patients. Ther Apher Dial. 2014;18:414-20.

20. Hirai T, Sugiya N, Nakashima A, Takasugi N, Yorioka N. Switching from epoetin alpha to darbepoetin alpha in Japanese hemodialysis patients: dose conversion ratio. Nephron Clin Pract. 2009;111:C81-86.

21. Wagner M, Alam A, Zimmermann J, Rauh K, Koljaja-Batzner A, Raff U, et al. Endogenous erythropoietin and the association with inflammation and mortality in diabetic chronic kidney disease. Clin J Am Soc Nephrol. 2011:6:1573-9.

22. Gejyo F, Saito A, Akizawa T, Akiba T, Sakai T, Suzuki M, et al. Japanese Society for Dialysis Therapy guidelines for renal anemia in chronic hemodialysis patients. Ther Apher Dial. 2004;2004(8):443-59.

23. Bazeley J, Bieber B, Li Y, Morgenstern H, de Sequera P, Combe C, et al. C-reactive protein and prediction of 1-year mortality in prevalent hemodialysis patients. Clin J Am Soc Nephrol. 2011;6:2452-61.

\section{Submit your next manuscript to BioMed Central and we will help you at every step:}

- We accept pre-submission inquiries

- Our selector tool helps you to find the most relevant journal

- We provide round the clock customer support

- Convenient online submission

- Thorough peer review

- Inclusion in PubMed and all major indexing services

- Maximum visibility for your research

Submit your manuscript at www.biomedcentral.com/submit
Biomed Central 